\title{
A Multi-Criteria Analysis Model for Investment Projects in Smart Cities
}

\author{
Antonio Nesticò ${ }^{*}++\left(\right.$ [D and Gianluigi De Mare ${ }^{\dagger}$ \\ Department of Civil Engineering, University of Salerno, 84084 Fisciano, Italy; gdemare@unisa.it \\ * Correspondence: anestico@unisa.it; Tel.: +39-089-964-319 \\ + The contribution to this paper is the result of the joint work of both Authors, to which the paper has to be \\ attributed in equal parts.
}

Received: 22 February 2018; Accepted: 15 April 2018; Published: 23 April 2018

\begin{abstract}
A city plays a central role in the processes of economic, social, and environmental development, becoming the core of policy makers' strategies. Thus, it is essential to optimize the use of monetary resources available by means of integrated decision-support approaches, able to pursue an increasingly "instrumented, interconnected and intelligent" cities prototype. In this perspective, the Smart City paradigm addresses the challenges of sustainable development through the implementation of new spatial planning schemes, which require the selection of projects on the basis of multi-criteria economic evaluation logics, namely financial and extra-financial criteria. The purpose of the work is to define an innovative model of economic analysis for the choice of investments in a Smart City, useful for both public operators and private investors. The evaluation protocol is written in the A Mathematical Programming Language (AMPL) through the optimization algorithms of Discrete Linear Programming (DLP). The effectiveness, adaptability, and operational simplicity of the investigative tool are tested on a case study. The model's limitations and research perspectives are highlighted in the conclusions of the work.
\end{abstract}

Keywords: economic evaluation; optimization algorithms; multicriteria models; sustainability; smart city

\section{Multi-Criteria Economic Evaluation for Smart Urban Planning}

In an era marked by rapid population growth, the scarcity of available resources, and the increase of pollutants in the atmosphere, government policies of the contemporary city seek useful actions to create an ever more "instrumented, interconnected and intelligent" cities model in accordance with urban sustainability principles [1-7]. Generally, these principles are not considered in economic evaluation models, which are often structured through algorithms that take into account a limited number of performance indicators, sometimes even of a purely financial nature. Thus, the analysis tool becomes weak because it is not very sensitive to real-world changes $[8,9]$.

Consequently, integrated decision-support approaches are required, through which urban planning actions are favored thanks to the employment of alternative technologies aimed at creating a highly efficient, equitable, sustainable, and livable city $[10,11]$. The city space regains its multidimensional nature through conscious use of a "[ ... ] new generation of integrated hardware, software and network technologies that provide Information Technology systems and real-time awareness of the real world and advanced analytic and actions that optimize business process", according to Chourabi et al. [7]. The built-up area is reconfigured, with the aim of optimizing technological advancement and conscious use of available resources. According to Harrison et al. [5]: "The Smart City connects the physical, IT, social and business infrastructure to leverage the collective intelligence of the city". 
At an operational level, the economic disciplines provide analytical models constructed according to logical multi-criteria, which allow the evaluation of Smart City initiatives based not only on financial criteria, but also on social, cultural, and environmental criteria [12-14].

This paper highlights the core components of spatial planning processes, particularly in relation to the logic of a Smart City. Starting from a review of the Operations Research tools, it shows that Discrete Linear Programming (DLP) may be effective for the selection of investments aimed at achieving urban sustainability-all this, however, while considering the limitations of a model that intends to deal in quantitative terms, variables of extra-financial impact, such as the effects on employment, the benefits for cultural heritage, or the repercussions for climate change. In any case, specialized analyses of the components under examination can give satisfactory reliability to the results of the study.

A multi-criteria approach is therefore proposed for the optimal allocation of financial resources in investment projects. The model, written with A Mathematical Programming Language (AMPL) in the logic of DLP is tested for the definition of an intervention program for the smart growth of a large area.

\section{The Smart City's Core Components}

The complexity of real phenomena leads to the search for innovative models of urban management capable of addressing the growth of the territory according to multicriterial logic $[15,16]$. In fact, the city is "the system of the systems" (Chourabi et al. [7]) in which the social, cultural, and environmental dimensions are linked to the purely financial reality in a biunivocal correspondence relationship [17].

The Intelligent City paradigm describes a systemic approach, like an organism, that develops an artificial nervous system, enabling it to behave in an intelligently coordinated way [18].

In particular, the interaction between Technological, Institutional, and Human Factors (Table 1), or rather among Smart City key conceptual components [19], creates an urban reality in which the "investments in human/social capital and IT infrastructure fuel sustainable growth and enhance a quality of life, through participatory governance" [20].

Table 1. Smart city core components.

\begin{tabular}{ccc}
\hline & SMART CITY & \\
\hline Technological Factors & Institutional Factors & Human Factors \\
\hline Digital City & Smart Community & Creative City \\
Intelligent City & Smart Growth & Learning City \\
Ubiquitous City & & Humane City \\
Wired City & & Knowledge City \\
Hybrid City & & \\
Information City & & \\
\hline
\end{tabular}

Three categories of representative factors of the Intelligent City are identified, from which are derived models of territory analysis useful for defining the strategic directions typical of smart planning. These include the British Standard Institute (BSI) model of the British Standard Institute, that of the city of Santander in Spain, and the SACERT system, all of which create the image of a city-system taking into account both financial and non-financial dimensions, according to an integrative logic favoured by Information and Communication Technology (ICT): “a ubiquitous/pervasive computing infrastructure is a key technological component in the build out of a digital city" [21].

The SACERT system in particular, with reference to the model represented in The Smart Cities Wheel of the American Fast Company \& Inc. (New York, NY, USA) [22], is identified as a useful framework for smart growth of the city, based on the economic (Smart Economy), environmental (Smart Environmental), and social (Smart People) dimensions, as well as on the governance, living, and mobility sectors.

The set of these components defines a city that is not only technologically advanced, but also "the organic and various set of physical, economic, intellectual and social capital", as reported by the 
Centre of Regional Science [23]. The Smart City Initiatives are combined with an infrastructure of communication and sustainable economic development, as well as with a high quality of life and an optimal management of resources, thanks to a participatory governance.

Consequently, territorial planning must proceed with multicriterial logic through the following phases:

(1) Identification of multiple goals-financial, social, cultural, environmental-to be achieved through the execution of projects;

(2) definition of criteria that can measure the capacity of actions to pursue different objectives. The criterion is "a principle or standard by which anything can be judged" [24]. Similarly, the criterion is "the lens through which to determine if the project is a success or a failure" [25];

(3) attributing a performance indicator to each criterion.

Obviously, the optimal selection of investment projects is essential. To this end, optimization algorithms are of great benefit, as they can simultaneously take into account more evaluation criteria by writing a mathematical expression that represents the objective function [26]. In the sense exposed, Operations Research provides alphanumeric tools for analytical models that are easily adaptable to the different dimensions of the Smart City.

\section{Optimization Algorithms for Smart City Initiatives}

Operations Research provides tools to support decision-making activities. This also applies to the selection of urban investment, where it is necessary to manage limited resources in order to maximize (or minimize) an objective function subject to constraints [27-29].

In particular, the techniques of linear programming allow the multidimensionality of spatial planning to be addressed, which can find synthesis within a single algebraic structure capable of taking into account the entire network of relations and the various city components [30].

In the construction of a mathematical analysis model, the decision is formalized as an optimization problem of the following type:

$$
\left\{\begin{array}{c}
\max (\mathrm{o} \min ) \mathrm{C}\left(x_{1}, \ldots, x_{n}\right) \\
\varphi_{m}\left(x_{1}, \ldots, x_{n}\right) \leq b_{m} \\
x \in \mathrm{X}
\end{array}\right.
$$

in which the objective function $C(x)$, the system of constraints $\varphi_{m}$ and the set of variables $x$ appear [31]. The mathematical programming problems are classified in:

1. Linear programming problems, if the objective function and the functions defining the constraints are linear, and

2. non-linear programming problems, if at least one of the problem functions is not linear.

In their turn, linear programming problems can be:

a. $\quad$ Of continuous optimization, if the $x$ vector assumes values in $R^{n}$;

b. of integer (or discrete) optimization, when the variables considered assume values in $Z^{n}$;

c. mixed, when the variables assume both integer and continuous value.

In the context of discrete linear programming, the problem may be:

1. Pure integer linear optimization, when $x$ decision variables are bound to assume values in the Z+ set;

2. binary or boolean optimization if, instead, the condition of entirety $x \in Z_{+}^{n}$ is more restrictive and it imposes that the variables assume only values 0 and 1 , or else $x \in\{0,1\}$, with the meaning of chosen $\{1\}$ and not chosen $\{0\}$.

In all of the above cases, it is necessary to select the algorithm solver for the problem under examination. For the integer linear programming, among the most used resolution algorithms 
recognized are those of dynamic programming, implicit enumeration such as the Branch \& Bound $(B \& B)$ algorithm, cutting planes algorithms, and the Branch \& Cut $(B \& C)$ algorithm $[32,33]$.

In the context of urban planning and design, the selection problems can often be solved through the use of simple mathematical models characterized by the entirety constraint $(x \in\{0,1\})$ placed on the decision variables. It is worth mentioning the well-known knapsack problem, where the objects are chosen in function of each of their values, and of the maximum capacity of the knapsack.

With the aim of pursuing the $m$ Smart City goals, with $m>1$, the selection problem arises between $n$ projects, not all of which are eligible for budget constraints. Because a single project cannot be fractionated, it is possible to implement the algorithms of DLP [34]. Among these algorithms, the B\&C algorithm is selected, which combines the cutting planes method with that of the B\&B algorithm.

In the paragraph that follows, a model for the optimal allocation of funds to be invested in a Smart City is written with the syntax of AMPL.

\section{A Multi-Criteria Economic Evaluation Model for Smart Cities}

The model is written in Table 2 using the programming environment AMPL [35]. The CPLEX solver is used. The B\&C optimization algorithm is implemented, which can solve integer linear programming problems.

Table 2. Evaluation Protocol.

\begin{tabular}{l}
\hline Projects Portfolio Selection Problem \\
\hline Sets \\
\hline set PROJECTS; \\
set PROJECTS_TYPE $1 ;$ \\
set PROJECTS_TYPE $2 ;$ \\
$\vdots$ \\
\hline set PROJECTS_TYPE $k$; \\
set EVALUATION CRITERIA; \\
\hline Parameters \\
\hline param BUDGET; \\
\hline param INDICATORS_unit $\{$ PROJECTS, EVALUATION CRITERIA $\} ;$ \\
\hline param COST $\{$ PROJECTS $\} ;$ \\
\hline Variables \\
\hline var $x\{i$ in PROJECTS $\}$ binary; \\
\hline Objective Function \\
\hline maximize (or minimize) objective: sum $\{i$ in PROJECTS, $j$ in INDICATORS $\}$ INDICATORS_unit $[i, j] \times x[i] ;$ \\
\hline Constraints \\
\hline s.t. (subject to) constraints_0: sum $\{i$ in PROJECTS $\}$ COST $[i] \times x[i] \leq$ BUDGET; \\
s.t. (subject to) constraints_ $1:$ sum $\{j$ in PROJECTS_TYPE 1$\}$ y [f] $\geq 1 ;$ \\
$\vdots$ \\
\hline s.t. (subject to) constraints_m: sum $\{\mathrm{h}$ in PROJECTS_TYPE $k\} 1[\mathrm{~h}] \geq 1 ;$ \\
\hline
\end{tabular}


The $n$ projects to be realized in the urban area (set PROJECTS) distinguished from $k$ intervention sectors (set PROJECTS_TYPE) are evaluated according to $m$ sustainability indicators (set EVALUATION CRITERIA).

The numerical values that detail the proposed selection problem, namely:

- $\quad$ The available budget (param BUDGET);

- $\quad$ the multi-criteria matrix (param INDICATORS_unit \{PROJECTS, EVALUATION CRITERIA\}); and

- $\quad$ the vector of the investment costs for the $n$ projects (param COST \{PROJECTS\}), are reported in the PARAMETERS section.

The unknowns (var $x\{i$ in PROJECTS $\}$ binary) are binary, namely $x \in\{0,1\}$, in consideration of the selection problem characteristics to be decided.

The objective function is written as:

MAXIMIZE (or MINIMIZE) objective: sum $\{i$ in PROJECTS, $j$ in INDICATORS $\}$

INDICATORS_unit $[i, j] \times x[i]$.

The constraint system (CONSTRAINTS) takes into account the total financial available allocation:

$$
\text { s.t. vinc_0: } \operatorname{sum}\{i \text { in PROJECTS }\} \text { COST }[i] \times x[i] \leq \text { BUDGET, }
$$

but also the necessity of ensuring the execution of at least one intervention for each individualized project class:

$$
\text { s.t. (subject to) CONSTRAINTS_1: sum }\{j \text { in PROJECTS_TYPE } 1\} \text { y [f] } \geq 1
$$

Operationally, the use of the programming environment AMPL allows the decision maker to:

- $\quad$ Build a model in parametric form through the .mod file;

- $\quad$ write the data about the problem in a .dat file separated by the corresponding .mod file;

- $\quad$ characterize the elements of the system as a set of objects (set);

- $\quad$ define the value of unknowns, i.e., the projects to be selected (var $x$ binary);

- $\quad$ structure the objective function as a linear algebraic expression that maximizes investment capability to pursue the many goals associated with sustainable city planning.

The model written in Table 2 assumes that all indicators have the same importance for the decision maker. They may also take into account different weights by simply multiplying by $p_{j}$ coefficients the values assumed by the projects evaluated with respect to the $j$-th criterion. This demonstrates the extreme versatility of the proposed analysis scheme.

\section{Case Study}

A set of 40 projects are considered, submitted for public funding, and aimed at the urban planning of a wide area in the province of Salerno (Italy) according to smart planning logic (Table 3). Because of the limited budget available, which does not allow all initiatives to be funded, it is necessary to select those projects able to determine the best financial, social, cultural, and environmental impacts on the territory.

On the basis of the smart city key factors, the $i$-th project is evaluated in accordance with the following five objectives:

a. financial implications;

b. employment effects;

c. reduction of air pollutants, also thanks to the use of renewable energy sources;

d. implementation of new technologies for better utilization of the services for the city;

e. urban equalization. 
Table 3. Multi-criteria analysis matrix.

\begin{tabular}{|c|c|c|c|c|c|c|c|c|}
\hline Smart Sectors & & Projects & IRR (\%) & $\begin{array}{c}\mathbf{N}^{\circ} \text { of } \\
\text { Workers }\end{array}$ & $\begin{array}{c}\mathrm{CO}_{2} \\
\text { (Thousands of } \\
\text { Tons per Year) }\end{array}$ & $\begin{array}{l}\mathbf{N}^{\circ} \text { of } \\
\text { ICT }\end{array}$ & IMPA & $\begin{array}{c}\text { COST } \\
\text { (Thousands of } € \text { ) }\end{array}$ \\
\hline \multirow{10}{*}{$\begin{array}{c}\text { SMART } \\
\text { ENVIRONMENTAL } \\
\text { ENERGY }\end{array}$} & 1 & URBAN ENERGY CONSUMPTION MONITORING SYSTEM & 6.70 & 2 & -1 & 3 & 7 & 1000 \\
\hline & 2 & ALTERNATIVE ENERGIES FOR SCHOOL BUILDINGS & 8.10 & 3 & -3 & 6 & 5 & 4300 \\
\hline & 3 & USE OF PHOTOVOLTAIC PANELS & 4.08 & 1 & -5 & 1 & 3 & 3800 \\
\hline & 4 & NEW TREATMENT PLANT & 5.14 & 12 & 1 & 0 & 1 & 5000 \\
\hline & 5 & GEOTHERMAL SYSTEM FOR PUBLIC BUILDINGS & 6.05 & 4 & -3 & 2 & 5 & 4850 \\
\hline & 6 & EFFICIENCY OF CITY'S ELECTRONIC GRID & 10.20 & 1 & -2 & 2 & 3 & 3000 \\
\hline & 7 & NEW METHANE GAS PLANT & 8.30 & 5 & -2 & 2 & 3 & 3150 \\
\hline & 8 & ALTERNATIVE ENERGY SYSTEMS FOR RESIDENTIAL CONSTRUCTION & 9.10 & 6 & -3 & 1 & 3 & 7125 \\
\hline & 9 & RECLAMATION OF CONTAMINATED SOILS & 6.20 & 3 & -1 & 0 & 9 & 4560 \\
\hline & 10 & THERMOMETRIC SURVEYING FOR HISTORICAL BUILDINGS & 4.50 & 5 & 0 & 2 & 3 & 4120 \\
\hline \multirow{12}{*}{$\begin{array}{l}\text { SMART LIVING } \\
\text { LIFE \& HEALTH }\end{array}$} & 11 & URBAN GARDENS & 7.55 & 10 & -3 & 2 & 5 & 2230 \\
\hline & 12 & AIR QUALITY MONITORING SYSTEMS & 5.10 & 2 & 0 & 1 & 5 & 2000 \\
\hline & 13 & SENSOR NETWORKS FOR ENVIRONMENTAL EMERGENCIES & 6.25 & 3 & -1 & 4 & 3 & 5210 \\
\hline & 14 & ENVIRONMENTALLY SUSTAINABLE URBAN RENEWAL & 9.30 & 1 & -4 & 4 & 7 & 5748 \\
\hline & 16 & DIGITAL ENHANCEMENT OF CULTURAL HERITAGE & 11.20 & 4 & 0 & 5 & 3 & 1838 \\
\hline & 17 & STRUCTURES FOR EDUCATIONAL SCHOOL CANTEEN & 5.35 & 10 & -1 & 1 & 5 & 5370 \\
\hline & 18 & INTEGRATED AGRO-ECOLOGICAL SYSTEMS & 7.33 & 15 & -2 & 1 & 7 & 2200 \\
\hline & 19 & CULTURAL INFORMATION CENTRE & 8.00 & 12 & 3 & 5 & 3 & 2850 \\
\hline & 20 & POLE FOR THE HEALTH PREVENTION & 5.40 & 16 & 0 & 4 & 3 & 2110 \\
\hline & 21 & SUPPORT SERVICES FOR DISABLED PEOPLE & 6.00 & 15 & 0 & 1 & 5 & 3700 \\
\hline & 22 & INTERVENTIONS AGAINST EARLY SCHOOL-LEAVING & 4.50 & 4 & 0 & 2 & 5 & 2300 \\
\hline & 23 & NEW ARCHAEOLOGICAL PARK & 7.60 & 3 & 0 & 3 & 3 & 3560 \\
\hline
\end{tabular}


Table 3. Cont.

\begin{tabular}{|c|c|c|c|c|c|c|c|c|}
\hline Smart Sectors & & Projects & IRR (\%) & $\begin{array}{c}\mathbf{N}^{\circ} \text { of } \\
\text { Workers }\end{array}$ & $\begin{array}{c}\mathrm{CO}_{2} \\
\text { (Thousands of } \\
\text { Tons per Year) }\end{array}$ & $\begin{array}{l}\mathrm{N}^{\circ} \text { of } \\
\text { ICT }\end{array}$ & IMPA & $\begin{array}{c}\text { COST } \\
\text { (Thousands of } € \text { ) }\end{array}$ \\
\hline \multirow{8}{*}{$\begin{array}{c}\text { SMART MOBILITY } \\
\text { ALTERNATIVE } \\
\text { SYSTEMS }\end{array}$} & 24 & ALTERNATIVE MOBILITY INITIATIVES & 9.50 & 6 & -3 & 2 & 3 & 2160 \\
\hline & 25 & BIKE-SHARING SYSTEMS & 6.50 & 3 & -4 & 2 & 3 & 1617 \\
\hline & 26 & ACTIONS FOR ELECTRICAL MOBILITY & 6.60 & 6 & -5 & 3 & 3 & 5895 \\
\hline & 27 & IMPROVEMENT OF COMMODITIES DISTRIBUTION & 6.75 & 1 & -1 & 1 & 5 & 9200 \\
\hline & 28 & MOBILITY MANAGEMENT SERVICES & 10.20 & 4 & -1 & 4 & 1 & 8000 \\
\hline & 29 & INFO-MOBILITY INTEGRATED PLATFORMS & 5.26 & 2 & -1 & 6 & 3 & 7116 \\
\hline & 30 & ASSISTED MOBILITY SERVICES & 8.50 & 8 & 3 & 3 & 3 & 2500 \\
\hline & 31 & ROAD MAINTENANCE & 5.40 & 8 & 0 & 1 & 5 & 1600 \\
\hline \multirow{9}{*}{$\begin{array}{l}\text { SMART PEOPLE } \\
\text { INCLUSION }\end{array}$} & 32 & SUPPORT SERVICES FOR THE ELDERLY & 8.10 & 22 & 0 & 3 & 9 & 8120 \\
\hline & 33 & CONSTRUCTION OF SOCIAL APARTMENT BUILDINGS & 7.20 & 2 & 1 & 2 & 7 & 7800 \\
\hline & 34 & OPEN-DATA TOOLS FOR INTEGRATED PLANNING & 9.45 & 5 & 0 & 4 & 3 & 1110 \\
\hline & 35 & CREATION OF SOCIAL ENTERPRISES & 5.20 & 16 & 1 & 1 & 5 & 4860 \\
\hline & 36 & NEW CULTURAL CENTER & 10.20 & 8 & 0 & 4 & 5 & 6750 \\
\hline & 37 & FACILITY FOR EMIGRANTS & 6.80 & 18 & 2 & 0 & 7 & 5110 \\
\hline & 38 & CITY ORATORY & 4.60 & 1 & 0 & 1 & 7 & 3256 \\
\hline & 39 & YOUTH HOSTEL & 10.70 & 8 & 3 & 2 & 5 & 4560 \\
\hline & 40 & URBAN CIVIC NETWORKS & 7.40 & 4 & 0 & 4 & 3 & 1230 \\
\hline
\end{tabular}

IRR: Internal Rate of Return; ICT: Information and Communication Technology; IMPA: Indicator in growing measure as the project's ability to generate new wealth in those districts with a higher level of degradation. 
The following corresponding performance indicators are assumed:

a. $\quad$ the Internal Rate of Return (IRR);

b. the number of new employees that the project produces ( $\mathrm{N}^{\circ}$ OF WORKERS);

c. the lowest $\mathrm{CO}_{2}$ emissions in the atmosphere, in terms of thousands of tons per year (the numerical values are positive-i.e., detrimental for selection purposes-in the case of $\mathrm{CO}_{2}$ emissions, while they are negative where the project causes $\mathrm{CO}_{2}$ destruction, such as for urban recovery initiatives that create new green spaces);

d. the amount of digital services information offered by the project for the fruition of the service ( $\mathrm{N}^{\circ}$ ICT);

e. the geographic location of the operation. A numeric value in the Saaty ordinal scale is attributed to the indicator (IMPA) in growing measure as the project's ability to generate new wealth in those districts with a higher level of degradation, which therefore require useful actions in pursuit of the highest urban standards found in other city areas.

The comparison of the project's initiatives' attributes requires the definition of a common measurement scale, obtained by normalizing each attribute through the equation:

$$
z_{i j}=\frac{x_{i j}-\mu_{j}}{\sigma_{j}}
$$

where $x_{i j}$ identifies the value taken on by the $i$-th project evaluated according to the $j$-th indicator, $\mu_{j}$ states the arithmetic average of the values assumed by the $n$ projects assessed according to the same $j$-th indicator, $\sigma_{j}$ is the standard deviation of the values $x_{i j}$ corresponding to the $j$ indicator.

The mathematical model explained in Section 4 is implemented using the normalized data.

The list of projects is constructed by associating each project with the binary value $\{0,1\}$, depending on whether the $i$-th investment is chosen (value 1 ) or not (value 0 ).

The model of the selection problem in question is expressed in the following mathematical form:

$$
\begin{gathered}
\left\{\text { max }_{i}\left(\text { irr }_{i}+n^{\circ} \text { of } \text { workers }_{i}+(- \text { emissions })_{i}+n^{\circ} \text { of } \text { ict }_{i}+\text { impa }_{i}\right) \times x_{i} \sum_{i=1}^{40} C_{i} \times x_{i}\right. \\
\leq \text { budget } \sum_{i=1}^{10} x_{i} \geq 1 \sum_{i=11}^{23} x_{i} \geq 1 \sum_{i=24}^{31} x_{i} \geq 1 \sum_{i=32}^{40} x_{i} \geq 1 x_{i} \in\{0,1\} \quad(i=1, \ldots, n)
\end{gathered}
$$

in which the objective function, the constraint regarding the available budget, and the necessity of ensuring the selection of at least one project for each Smart Sector are written.

In the AMPL programming environment, the .mod file in Table 2 is associated with the dat file (Table 4), that returns the results of the multi-criteria analysis performed for each of the 40 projects set out in Table 3. 
Table 4. Dat file written in AMPL.

\begin{tabular}{|c|c|c|c|c|c|c|}
\hline \multicolumn{7}{|c|}{ Dat File } \\
\hline \multicolumn{7}{|c|}{$\begin{array}{l}\text { set PROJECTS: = } 123456789101112131415161718192021222324252627282930313233343536 \\
373839 \text { 40; }\end{array}$} \\
\hline \multicolumn{7}{|c|}{ set INDICATORS: = IRR N.W. $\mathrm{CO}_{2}$ ICT IMPA; } \\
\hline \multicolumn{3}{|c|}{ param INDICATORS_unit: = } & \multicolumn{4}{|c|}{ param COST: = } \\
\hline IRR & & N.W. & $\mathrm{CO}_{2}$ & ICT & IMPA & \\
\hline 1 & 0.6 & 0.09 & -0.33 & 0.5 & 0.78 & 1000 \\
\hline 2 & 0.72 & 0.14 & -1 & 1 & 0.56 & 4300 \\
\hline 3 & 0.36 & 0.05 & -1.67 & 0.17 & 0.33 & 3800 \\
\hline 4 & 0.46 & 0.55 & 0.33 & 0 & 0.11 & 5000 \\
\hline 5 & 0.54 & 0.18 & -1 & 0.33 & 0.56 & 4850 \\
\hline 6 & 0.91 & 0.05 & -0.67 & 0.33 & 0.33 & 3000 \\
\hline 7 & 0.74 & 0.23 & -0.67 & 0.33 & 0.33 & 3150 \\
\hline 8 & 0.81 & 0.27 & -1 & 0.17 & 0.33 & 7125 \\
\hline 9 & 0.55 & 0.14 & -0.33 & 0 & 1 & 4560 \\
\hline 10 & 0.4 & 0.23 & 0 & 0.33 & 0.33 & 4120 \\
\hline 11 & 0.67 & 0.45 & -1 & 0.33 & 0.56 & 2230 \\
\hline 12 & 0.46 & 0.09 & 0 & 0.17 & 0.56 & 2000 \\
\hline 13 & 0.56 & 0.14 & -0.33 & 0.67 & 0.33 & 5210 \\
\hline 14 & 0.83 & 0.05 & -1.33 & 0.67 & 0.78 & 5748 \\
\hline 15 & 0.71 & 0.55 & 0 & 0.83 & 0.11 & 1300 \\
\hline 16 & 1 & 0.18 & 0 & 0.83 & 0.33 & 1838 \\
\hline 17 & 0.48 & 0.45 & -0.33 & 0.17 & 0.56 & 5370 \\
\hline 18 & 0.65 & 0.68 & -0.67 & 0.17 & 0.78 & 2200 \\
\hline 19 & 0.71 & 0.55 & 1 & 0.83 & 0.33 & 2850 \\
\hline 20 & 0.48 & 0.73 & 0 & 0.67 & 0.33 & 2110 \\
\hline 21 & 0.54 & 0.68 & 0 & 0.17 & 0.56 & 3700 \\
\hline 22 & 0.4 & 0.18 & 0 & 0.33 & 0.56 & 2300 \\
\hline 23 & 0.68 & 0.14 & 0 & 0.5 & 0.33 & 3560 \\
\hline 24 & 0.85 & 0.27 & -1 & 0.33 & 0.33 & 19,500 \\
\hline 25 & 0.58 & 0.14 & -1.33 & 0.33 & 0.33 & 11,560 \\
\hline 26 & 0.59 & 0.27 & -1.67 & 0.5 & 0.33 & 6600 \\
\hline 27 & 0.6 & 0.05 & -0.33 & 0.17 & 0.56 & 6750 \\
\hline 28 & 0.91 & 0.18 & -0.33 & 0.67 & 0.11 & 16,200 \\
\hline 29 & 0.47 & 0.09 & -0.33 & 1 & 0.33 & 5260 \\
\hline 30 & 0.76 & 0.36 & 1 & 0.5 & 0.33 & 2500 \\
\hline 31 & 0.48 & 0.36 & 0 & 0.17 & 0.56 & 1600 \\
\hline 32 & 0.72 & 1 & 0 & 0.5 & 1 & 8125 \\
\hline 33 & 0.64 & 0.09 & 0.33 & 0.33 & 0.78 & 7800 \\
\hline 34 & 0.84 & 0.23 & 0 & 0.67 & 0.33 & 1100 \\
\hline 35 & 0.46 & 0.73 & 0.33 & 0.17 & 0.56 & 4860 \\
\hline 36 & 0.91 & 0.36 & 0 & 0.67 & 0.56 & 6750 \\
\hline 37 & 0.61 & 0.82 & 0.67 & 0 & 0.78 & 5110 \\
\hline 38 & 0.41 & 0.05 & 0 & 0.17 & 0.78 & 3256 \\
\hline 39 & 0.96 & 0.36 & 1 & 0.33 & 0.56 & 4560 \\
\hline 40 & 0.66 & 0.18 & 0 & 0.67 & 0.33 & 1230; \\
\hline
\end{tabular}

The .mod and .dat files are entered into the AMPL command line, specifying the solver that implements the $\mathrm{B} \& \mathrm{C}$ algorithm:

ampl: reset;

ampl: model FILE.mod;

ampl: data FILE.dat;

ampl: option solver cplex;

ampl: solve. 
The resultant optimal combination is made up of the projects:

1-11-16-18-19-20-21-22-23-30-31-34-35-40.

The corresponding objective function value is 27.98 , and the total cost of investment is $€ 33,088$. The available budget of $€ 33,500,000$ is almost entirely used.

With an $\varepsilon$-constrained type algorithm, a further constraint can be imposed on the problem:

$$
\text { objective } i \leq \text { objective }(i-1)-\varepsilon
$$

so as to extrapolate, with $\varepsilon=1 \%$, the list of the best combinations of projects. Table 5 shows the first seven combinations, associating to each project the value of the objective function and the investment cost.

Table 5. List of the best combinations of projects.

\begin{tabular}{cccc}
\hline & Combination of Projects & Objective Function & Costs (in Thousands of $\boldsymbol{€}$ ) \\
\hline 1 & $1-11-16-18-19-20-21-22-23-30-31-34-35-40$ & 27.98 & 33,088 \\
2 & $1-11-15-16-18-19-21-22-23-30-31-34-35-40$ & 27.97 & 32,270 \\
3 & $1-7-11-15-16-18-20-22-30-31-34-37-39-40$ & 27.96 & 32,238 \\
4 & $1-15-16-19-20-22-23-30-31-32-34-39$ & 27.95 & 32,853 \\
5 & $1-6-11-12-15-16-18-20-23-30-31-34-38-39-40$ & 27.94 & 33,494 \\
6 & $1-11-15-16-18-19-20-21-22-23-30-31-34-40$ & 27.93 & 29,528 \\
7 & $1-11-15-16-18-19-20-21-22-23-29-30-34-40$ & 27.92 & 33,188 \\
\hline
\end{tabular}

The analysis conducted so far assumes that all five evaluation criteria have the same importance. It is possible to attribute different weights to the indicators by writing the maximization function, which takes the following form:

$$
\max \sum_{i}(p 1 * I R R i+p 2 * N W i+p 3 * \text { EMISSIONSi }+p 4 * I C T i+p 5 *(I M P A) i) * x i,
$$

where $p_{1}, \ldots, p_{5}$ are the coefficients able to "weigh" the indicators between them.

\section{Conclusions}

The Smart City model enhances the multidimensionality of urban reality, where the multiple economic, social, cultural, and environmental components converge. The conscious inclusion of technological innovation in the systemic structure of the city promotes the use of renewable energy sources, functional virtualization aimed at reducing the intensity of land use, and the promotion of alternative mobility systems. Consequently, investment decisions require selection processes that do not disregard the implementation of principles and techniques typical of the multi-criteria economic evaluation.

The present work proposes a model of economic analysis built according to the rules of Operations Research, with the aim of choosing the optimal combination of projects to be financed in the context of sustainable development of the urban territory. The protocol allows not only the public operator, but also the private investor, who must choose how best to allocate the available resources, to consistently define an investment program able to pursue multiple objectives, while also taking into account budget limits and other constraints imposed by the system under examination. In fact, information derived from multi-criteria analysis is associated with the evaluation algorithm, which is written in AMPL. Objective functions and constraint conditions are expressed in terms of DLP.

If, on the one hand, the limitations are evident of a protocol that treats in quantitative terms qualitative variables regarding extra-financial impacts, on the other hand, it should also be noted that 
specialized analyses of social, cultural, or environmental repercussions can give satisfactory reliability to the results of the model's applications. Future research must go in this direction.

The case study concerns the selection of projects for a Smart City. It demonstrates the effectiveness and simplicity of the implementation of the evaluation scheme, which can establish the optimum combination of investment initiatives that will maximize the objective function value. The possibility of easily modifying the calculation algorithm, and of "weighing" the estimation criteria in the maximization function, also attests to the model's adaptability to different real-world situations.

Author Contributions: Antonio Nesticò and Gianluigi De Mare together conceived and designed the Multi-Criteria Analysis Model for Investment Projects in Smart Cities. For the case study, Antonio Nesticò performed the calculations and Gianluigi De Mare analyzed the data. Gianluigi De Mare and Antonio Nesticò jointly wrote the paper.

Conflicts of Interest: The authors declare no conflicts of interest.

\section{References}

1. Glaeser, E.L.; Scheinkman, J.A.; Shleifer, A. Economic Growth in a Cross-Section of Cities. J. Monet. Econ. 1995, 36, 117-143. [CrossRef]

2. Simon, C.J.; Nardinelli, C. Human Capital and the Rise of American Cities, 1900-1990. Reg. Sci. Urban Econ. 2002, 32, 59-96. [CrossRef]

3. Glaeser, E.L.; Shapiro, J.M. Urban Growth in the 1990s: Is City Living Back? J. Reg. Sci. 2003, 43, $139-165$. [CrossRef]

4. Johnson, B. Cities, systems of innovation and economic development. Innov. Manag. Policy Pract. 2008, 10, 146-155. [CrossRef]

5. Harrison, C.; Eckman, B.; Hamilton, R.; Hartswick, P.; Kalagnanam, J.; Paraszczak, J.; Williams, P. Foundations for smarter cities. IBM J. Res. Dev. 2010, 54, 1-16. [CrossRef]

6. Batty, M.; Axhausen, K.; Fosca, G.; Pozdnoukhov, A.; Bazzani, A.; Wachowicz, M.; Ouzounis, G.; Portugali, Y. Smart cities of the future. Eur. Phys. J. Spec. Top. 2012, 214, 481-518. [CrossRef]

7. Chourabi, H.; Nam, T.; Walker, S.; Gil-Garcia, J.R.; Mellouli, S.; Nahon, K.; Pardo, T.A.; Scholl, H.J. Understanding Smart Cities: An Integrative Framwork. In Proceedings of the 45th Hawaii International Conference on System Sciences, Maui, HI, USA, 4-7 January 2012; pp. 2289-2297. [CrossRef]

8. Chan, E.H.W.; Yung, E.H.K. Is the development control legal framework conducive to a sustainable dense urban development in Hong Kong? Habitat Int. 2004, 28, 409-426. [CrossRef]

9. De Mare, G.; Granata, M.F.; Nesticò, A. Weak and Strong Compensation for the Prioritization of Public Investments: Multidimensional Analysis for Pools. Sustainability 2015, 7, 16022-16038. [CrossRef]

10. Odendaal, N. Information and communication technology and local governance: Understanding the difference between cities in developed and emerging economies. Comput. Environ. Urban Syst. 2003, 27, 585-607. [CrossRef]

11. Tewdwr-Jones, M.; Allmendinger, P. Territory, Identity and Spatial Planning. Spatial Governance in a Fragmented Nation; Routledge: London, UK; New York, NY, USA, 2006.

12. Barbier, E.B. The Concept of Sustainable Economic Development. Environ. Conserv. 1987, 14, 101-110. [CrossRef]

13. Nesticò, A.; Galante, M. An estimate model for the equalisation of real estate tax: A case study. Int. J. Bus. Intell. Data Min. 2015, 10, 19-32. [CrossRef]

14. Nesticò, A.; Pipolo, O. A protocol for sustainable building interventions: Financial analysis and environmental effects. Int. J. Bus. Intell. Data Min. 2015, 10, 199-212. [CrossRef]

15. Fusco Girard, L.; Nijkamp, P. Le Valutazioni Integrate per lo Sviluppo Sostenibile Della città e del Territorio; FrancoAngeli: Milano, Italy, 1997.

16. Bencardino, M.; Nesticò, A. Demographic Changes and Real Estate Values. A Quantitative Model for Analyzing the Urban-Rural Linkages. Sustainability 2017, 9, 536. [CrossRef]

17. Dirks, S.; Keeling, M. A Vision of Smarter Cities. How Cities Can Lead the Way into a Prosperous and Sustainable Future; IBM: Somers, NY, USA, 2009.

18. Kanter, R.M.; Litow, S.L. Informed and Interconnected: A Manifesto for Smarter Cities. Available online: https:/ /hbswk.hbs.edu/item/informed-and-interconnected-a-manifesto-for-smarter-cities (accessed on 23 July 2009). 
19. Nam, T.; Pardo, T.A. Conceptualizing Smart City with Dimensions of Technology, People, and Institutions. In Proceedings of the 12th Annual International Conference on Digital Government Research (DG.O 2011), College Park, MD, USA, 12-15 June 2011.

20. Caragliu, A.; Del Bo, C.; Nijkamp, P. Smart cities in Europe. In Proceedings of the 3rd Central European Conference in Regional Science (CERS), Košice, Slovak Reublic, 7-9 October 2009; pp. 45-59.

21. Yovanof, G.S.; Hazapis, G.N. An architectural framework and enabling wireless technologies for digital cities and intelligent urban environments. Wirel. Pers. Commun. 2009, 49, 445-463. [CrossRef]

22. Available online: https://www.fastcompany.com/3038818/the-smartest-cities-in-the-world-2015-methodology (accessed on 4 April 2018).

23. Centre of Regional Science, Vienna University of Technology. Smart Cities. Ranking of European Medium-Sized Cities; Final Report; Vienna University of Technology: Vienna, Austria, 2007.

24. Lim, C.S.; Mohamed, M.Z. Criteria of project success: An explanatory re-examination. Int. J. Proj. Manag. 1999, 17, 243-248. [CrossRef]

25. Ika, L.A. Project success as a topic in project management journals. Int. J. Proj. Manag. 2009, 40, 6-19. [CrossRef]

26. Nesticò, A.; Sica, F. The sustainability of urban renewal projects: A model for economic multi-criteria analysis. J. Prop. Invest. Financ. 2017, 35, 397-409. [CrossRef]

27. Shapiro, J.M. Smart Cities: Quality of Life, Productivity, and the Growth Effects of Human Capital. Rev. Econ. Stat. 2006, 88, 324-335. [CrossRef]

28. Lazaroiu, G.C.; Roscia, M. Definition methodology for the smart cities model. Energy 2012, 47, $326-332$. [CrossRef]

29. De Mare, G.; Nesticò, A.; Macchiaroli, M. Significant appraisal issues in value estimate of quarries for the public expropriation. Valori e Valutazioni 2017, 18, 17-23.

30. Nesticò, A.; De Mare, G.; Sica, F. An Optimization Algorithm for the Selection of Investment Projects in Smart Cities. In Proceedings of the 15th International Conference on Environmental Science and Technology (CEST 2017), Rhodes, Greece, 31 August-2 September 2017.

31. Korte, B.; Vygen, J. Optimisation Combinatoire. Théorie et Algorithmes; Springer: Paris, France, 2010.

32. Ventura, P. Alcuni contributi alla separazione primale e duale per problemi di programmazione lineare intera. In Bollettino dell'Unione Matematica Italiana; Serie 8, 6-A; La Matematica nella Società e nella Cultura, Fasc. 2; CNR: Roma, Italy, 2003; pp. 335-338.

33. Vercellis, C. Ottimizzazione. Teoria, Metodi, Applicazioni; McGraw-Hill: Milano, Italy, 2008.

34. Thuesen, G.J.; Fabrycky, W.J. Economia per Ingegneri; Il Mulino: Bologna, Italy, 1994.

35. Bruglieri, M.; Cordone, R.; Liberti, L.; Iuliano, C. Manuale essenziale di AMPL; Dipartimento di Elettronica e Informazione; Politecnico di Milano: Milan, Italy, 2010. 